\title{
Morbidity Pattern and its Determinants among Tribal People in Kerala
}

\author{
T D Simon*
}

\section{Abstract}

While Kerala has been hailed for its development in social sectors, the available data show the remarkable finding that Kerala's morbidity is the highest in India. Literature reveals two major streams of argument for this, one questioning the comparability of the reported rates of morbidity and the other admitting that the higher rates of morbidity actually represent the situation. The present study analyses the pattern of morbidity in Kerala, tries to analyse the morbidity pattern and finds out the reasons for highest morbidity in highest Monthly Per Capita Consumption Expenditure (MPCE) group and lower morbidity in ST households. The paper argues that the prevalence of lifestyle diseases among highest MPCE group is one critical reason for the high morbidity rates in Kerala. It also proposes urgent interventions on behalf of the government that can effectively counter the high rates of infectious diseases among ST households.

Keywords: Morbidity, Morbidity syndrome, MPCE, Lifestyle diseases, Scheduled Tribe

\section{Introduction}

The impressive records of achievement in social segments like education and health including infant mortality, crude death rate and life expectancy at birth were some the prominent factors that

\footnotetext{
* Sree Keralavarma College, Thrissur, Kerala, India; tdsimon@gmail.com
} 
drew the international development experts' attention to Kerala's development experience. The health development of the state is generally attributed to the spread of basic education, public awareness through specific state programmes and advances in the sphere of infrastructure facilities. The easy access to medical care facilities is another critical factor in the state's remarkable performance in the health care sector (CDS-UN 1975; Nag 1983; Krishnan 1985; Navaneetham and Dharmalingam 2002). "The region was subsequently viewed as an exemplary case that could be invoked to demonstrate the general possibility of achieving high levels of social development even with very little economic advancement, and the so-called 'Kerala model' eventually became part of the global development discourse" (Government of Kerala 2006, p15).

There are, however, certain disturbing questions as far as its replicability and sustainability are concerned; this is despite the many positive matters visible in Kerala's development experience (Tharakan 2006; Veron 2000). "Although mortality remains at low levels, the state has a higher rate of morbidity (those suffering from diseases) compared to other Indian states. Hence, the Kerala situation is described as having 'Low Mortality High Morbidity Syndrome'" (Panicker and Soman 1985 cited in Ekbal 2006, p.38). "Infectious diseases like dengue fever, diarrhoea, leptospirosis, etc., are prevalent in Kerala much beyond their average occurrence anywhere else in the country. In addition the incidence of several lifestyle diseases is much beyond the national average" (Ekbal 2006, p.38).

There are two major streams of argument for the high morbidity in Kerala - one questioning the comparability of the reported rates of morbidity and the other admitting the higher rates of morbidity as actually representing the situation. In other words, the former argument highlights that the higher rate of morbidity is mainly arisen through higher reportability of cases of sickness which in turn is indebted to the higher educational levels and health care institutions prevailing in the state. On the contrary, the latter argument holds that there are ill-health conditions prevailing in the state which in turn causes higher morbidity. 
When we look into the relationship between the morbidity pattern and MPCE, two different pictures emerge. On the one hand, morbidity is very high among the highest MPCE group and, on the other hand, the lowest morbidity is reported among Scheduled Tribe group, who are considered to be the poorest of the poor. There is dearth of empirical studies which concentrate on the determinants of morbidity in Kerala. It is against this background that the present study is making an attempt to establish the right school of the thought pertaining to the morbidity syndrome in Kerala by analysing morbidity pattern and its determinants, giving special emphasis to Scheduled Tribe (ST) category. The present study is based on the unit level data of National Sample Survey Organisation's 71st Round 'Key Indicators of Social Consumption in India: Health'. The sample includes 11229 respondents from Kerala and the analysis has been done with projected population.

\section{The genealogy of discussions}

The low mortality levels of Kerala first received its major blow in 1973-74 when a National Sample Survey reported that the state's morbidity rate was the highest in India (acute illness - 71 per 1,000 persons and Chronic illness - 83 per 1,000)(Government of Kerala 2006). Subsequently, surveys conducted by agencies like Kerala Shastra Sahitya Parishath (KSSP)in 1987, National Council of Applied Economic Research in 1992-93 and the 52nd Round of NSS data collected during 1995-96 confirmed high levels of acute and chronic morbidity in Kerala (Kannan et al. 1991; Kunhikannan and Aravindan 2000).In an important study, conducted by KSSP in 1987, it was argued that the reasons for Kerala's high morbidity were due to infectious diseases; the study also argued that poor people had more illness than the rich(Kannan et al. 1991). According to Ashokan and Ibrahim (2007), the poor are exposed to a relatively higher morbidity load compared to the non-poor.

Scholars, who considered higher morbidity as a positive indicator, tried to relate it with the remarkable educational system followed by the state. Amartya Sen (Sen 1987; 2002) was of the opinion that a population with high literacy rates have more possibilities to report illness due to the access to medical attention and health facilities. By comparing the morbidity pattern in Kerala and Bihar, he added 
that "there is much evidence that people in states that provide more education and better medical and health facilities are in a better position to diagnose and perceive their own particular illnesses than are the people in less advantaged states, where there is less awareness of treatable conditions (to be distinguished from "natural" states of being)" (Sen 2002, p.861). There were also people who thought that higher levels of literacy and better medical facilities help for an earlier diagnosis and detection of illness which further becomes the cause for the higher morbidity in Kerala(Gumber and Berman 1997). Krishnaswami (2004) found out that the morbidity rate tends to increase with educational and economic levels and there is also an indication that it tends to decrease with household size. As people in Kerala are highly educated and more aware, the ailments are easily diagnosed and these are often cited as reasons for high morbidity (Murray and Chen 1990, Kannan et al. 1991; Gumber and Berman 1997).

Ever since morbidity has taken over the focus of development scholarships in Kerala, these two arguments prevailed substantially. Albeit the facticity of both these arguments beyond any challenge, and both of them speak of two important and undeniable sides of Kerala's development experience, the actual occurrence of morbidity remained a case that definitely deserved to be addressed. Studies in this direction have come up with observations that talk about higher levels of morbidity among higher Monthly Per capita Consumption Expenditure (MPCE) groups (Dilip 2002).

But, at the same time, while surveying through the other group of studies, we can see that conditions of tribes in Kerala are distressing. In a study conducted among tribal people of Wayanad district of Kerala, it was found that Women from SC/ST and other background had poor health than the women from forward castes (Mohindra et al. 2006). Studies on rural health indicators show that the lowest social class including the tribes have highest death and birth rates (Kannan et.al 1991). While the situation more or less remains the same, tribes particularly are caught in the vicious circle of poverty coupled with malnutrition, morbidity and mortality. Majority of the tribes experience severe poverty. The study conducted by Scaria et al. (2013) confirms this; they observe that 
"Majority of tribes lies in the category of severe poverty, i.e., tribes in Attappady[in Palakkad district] are affected in more than 50\% deprivation indicators (they became poor due the lacking or in accessibilities of more than five lively hood indicators)" (p.238; emphasis mine).It is also reported that certain diseases like sickle-cell anaemia is prominent in tribal households (Devika and Rajasree 2008). Moreover pregnant women and lactating mothers are found to be suffering from chronic malnutrition and anaemia leading to high infant mortality rates (Ekbal et. al 2013).

\section{Trend, pattern of morbidity and its determinants}

For the purpose of the survey, "morbidity rate is termed as Proportion of Ailing Persons (PAP), measured as the number of living persons reporting ailment (per 1000 persons) during 15-day reference period for different gender in rural and urban sector" (NSSO 2014,p.10). Moreover, "ailment, i.e. illness or injury, meant any deviation from the state of physical and mental well-being" (p.B4).The morbidity pattern of Kerala during the $52^{\text {nd }}, 60^{\text {thand }} 71^{\text {st }}$ Rounds of NSSO is given in Table 1. The morbidity rate is reported as highest in Kerala both in Proportion of Ailing Persons (PAP) and reporting commencement of any ailment (PPC) ${ }^{1}$.

Table 1Number (per 1000) of Proportion of Ailing Persons (PAP)during last 15 days, for Kerala and India

\begin{tabular}{rlcc}
\hline \multicolumn{1}{c}{ Year } & \multicolumn{1}{c}{ Area } & Kerala & India* $^{*}$ \\
\hline \multirow{2}{*}{$1995-96$} & Rural & 118 & 55 \\
& Urban & 88 & 54 \\
2004 & Rural & 255 & 88 \\
& Urban & 240 & 99 \\
2014 & Rural & 310 & 89 \\
& Urban & 306 & 118 \\
\hline
\end{tabular}

${ }^{1}$ The PPC is measured as the proportion (number per 1000) of persons reporting commencement of any ailment during the reference period of 15 days preceding the date of survey. It may be noted that the PPC is different from incidence rate, as recommended by the W.H.O. Expert Commission on Health Statistics. While the incidence rate measures the frequency of illnesses commencing during a reference period, the PPC gives the estimated proportion of persons reporting commencement of any ailment (NSSO 1998, p.12). 
* Excludes Nagaland

Source: NSSO Reports Nos. 441, 507\&NSS KI (71/25.2)

PAP was reported as 255 in rural Kerala as against 88 in rural India in 2004. In urban area also Kerala reported highest PAP of 240 as against 99 which was the all India average at that time.

In this section, the relationship between morbidity and background variables like caste, MPCE, size of the household, age, place of residence, and sex is examined. Many authors have analysed the relationship between these background variables and morbidity. For having an idea about this relationship, some of the studies are cited below:

Caste plays an important role in deciding health population of a society. Iyer (2005) and Mohinidra et al. (2006).are of the opinion that there exists a close relationship between caste and health status. Monthly Per-capita Consumption Expenditure (MPCE) and prevalence of ailments are positively related (Dilip 2002; Ghosh and Arokiasamy 2009). Similarly, a positive association between morbidity and economic level has also been established (Krishnaswami 2004).It is to be noted here is that there is a tendency to consider MPCE as a proxy for the level of well-being or income status.

According to Mukherjee and Levesque, chronic non-communicable diseases are the major causative factors for morbidity among the elder population (Mukherjee and Levesque 2012). They claim that "out of five most frequently reported ailments by the elderly, four are related to chronic illnesses" (p.183). The studies conducted in Kerala shows that as far as the sex is considered, morbidity is higher among women than men (Suryanarayana 2008; Navaneetham et al. 2009). In the case of size of family, there exists inverse relationship between size of family and morbidity rate (Dilip 2002; Krishnaswami 2004) and the relationship between place of residence and morbidity shows that were reported higher rate of morbidity was reported in rural area (Suryanarayana 2008).

The above cited studies show that there definitely exists relationship between morbidity and selected background variables and an attempt is made in the following sections to discover the effect of selected background variables on health status of the population. 


\section{Relationship between morbidity and socio-economic characteristics}

The unit level data of National Sample Survey Organisation's 71st Round 'Key Indicators of Social Consumption in India: Health' (2014), with special reference to Kerala is analysed in this section. The Kerala sample includes 11229 respondents and the analysis has been done with projected population and the morbidity pattern is discussed among six socioeconomic variables. 30.8 per cent of the respondents in Kerala reported morbidity, while all India picture shows 9.8 per cent of morbidity (Table 2).

Among the caste groups, 'Others' group showed the highest morbidity (33.5 per cent) followed by 'Other Backward Sections' (30.3 per cent) and least morbidity was reported for Scheduled Tribes. Some specific pattern of changes can be seen in morbidity pattern from backward castes to forward castes. MPCE classification showed that low consumption group has low morbidity (31.9 per cent) and with an increase in consumption class the morbidity also increases, having highest MPCE group with 32 per cent.

As expected, old age group showed highest morbidity. Females reported more morbidity when compared to males. Household size and morbidity showed an inverse relationship. The highest morbidity rate was reported in lowest size group while the lowest morbidity was reported in highest household size group. Morbidity was higher in rural area when compared to urban area.

It is to be noted that the relationship between the morbidity pattern and monthly per capita consumption expenditure (MPCE) shows two different pictures. On the one hand, it is reported that highest level of morbidity (32 per cent) is among highest MPCE group, who can be considered as highest income group, but, on the other hand, the lowest morbidity rate (23.3 per cent) is reported among Scheduled Tribe group, who are considered to be the poorest of the poor. So, in this context, it is the time to find out the various reasons for this paradox in morbidity. For this purpose, the relationship between the type of disease and background variables will be analysed in the next session. 
Table 2 Morbidity status of respondents among different socio-economic groups in Kerala and India 2014 (percentage)

\begin{tabular}{|c|c|c|c|}
\hline \multirow{2}{*}{ Background variables } & \multirow{2}{*}{ Attributes } & \multicolumn{2}{|c|}{ Morbidity (Percentage) } \\
\hline & & Kerala & India \\
\hline \multirow{4}{*}{ Caste } & ST & 23.3 & 6.9 \\
\hline & SC & 28.4 & 9.2 \\
\hline & OBC & 30.3 & 9.8 \\
\hline & Others & 33.5 & 11.1 \\
\hline \multirow{3}{*}{$\begin{array}{l}\text { MPCE } \\
\text { Group }\end{array}$} & Low MPCE & 31.9 & 7.4 \\
\hline & Medium MPCE & 28.4 & 9.8 \\
\hline & High MPCE & 32.0 & 14.0 \\
\hline \multirow{5}{*}{$\begin{array}{l}\text { Age } \\
\text { Group }\end{array}$} & $0-4$ & 25.8 & 10.6 \\
\hline & $5-14$ & 15.8 & 5.5 \\
\hline & $15-34$ & 13.1 & 5.0 \\
\hline & $35-59$ & 37.7 & 12.8 \\
\hline & $60 \&$ above & 67.2 & 30.2 \\
\hline \multirow{3}{*}{ Sex } & Male & 29.2 & 8.7 \\
\hline & Female & 32.3 & 11.0 \\
\hline & $3 \&$ below & 41.4 & 15.5 \\
\hline \multirow{3}{*}{$\begin{array}{l}\text { Household } \\
\text { size }\end{array}$} & $4-5$ & 28.3 & 9.9 \\
\hline & $6-7$ & 28.3 & 7.9 \\
\hline & $8 \&$ Above & 24.2 & 6.8 \\
\hline \multirow{2}{*}{ Area } & Rural & 31.0 & 8.9 \\
\hline & Urban & 30.6 & 11.8 \\
\hline Total & & 30.8 & 9.8 \\
\hline
\end{tabular}

Source: Estimated from the unit level data of NSS $71^{\text {st }}$ Round, Key Indicators of Social Consumption in India: Health, 2014

\section{Nature of ailment}

Chronic ailment in the survey was identified that 20.8 per cent of the respondents in Kerala suffered from chorionic ailment whereas the all India figure stood 4.8 at percent. The connection between morbidity and chronic ailment is an important factor in caste and MPCE categories as well. While chronic ailment was high among the highest MPCE group the same was very low among the ST respondents. 
Table 3 Chronic ailment of respondents among different socio-economic groups in Kerala and India 2014 (Percentage)

\begin{tabular}{llrr}
\hline $\begin{array}{l}\text { Background } \\
\text { variables }\end{array}$ & Attributes & \multicolumn{2}{c}{$\begin{array}{c}\text { Chronic ailment } \\
\text { Kerala }\end{array}$} \\
\hline \multirow{3}{*}{ Caste } & ST & 6.4 & 2.0 \\
& SC & 20.1 & 4.0 \\
& OBC & 19.2 & 4.8 \\
MPCE & Others & 25.9 & 6.4 \\
Group & Low MPCE & 19.7 & 2.7 \\
Total & Medium MPCE & 17.5 & 4.7 \\
\hline
\end{tabular}

Source: Estimated from the unit level data of NSS $71^{\text {st }}$ Round, Key Indicators of Social Consumption in India: Health, 2014

As far as the Category of ailments is concerned,according to the available data the occurrence of cardio-vascular diseases is high in Kerala (Table 4). 21.3 per cent of the respondents suffered from this followed by endocrine, metabolic, nutritional type of diseases (19.3 per cent).

Table 4 Distribution of ailment group of morbid persons among different caste and MPCE groups (Percentage)

\begin{tabular}{|c|c|c|c|c|c|c|}
\hline \multirow[b]{2}{*}{$\begin{array}{c}\text { Back } \\
\text { ground } \\
\text { variables }\end{array}$} & \multirow[b]{2}{*}{$\begin{array}{l}\text { Attri } \\
\text { butes }\end{array}$} & \multicolumn{5}{|c|}{ Ailment group } \\
\hline & & $\begin{array}{l}\text { Cardio- } \\
\text { vascular }\end{array}$ & $\begin{array}{l}\text { Endocrine, } \\
\text { metabolic, } \\
\text { nutritional }\end{array}$ & Infection & $\begin{array}{l}\text { Respi- } \\
\text { ratory }\end{array}$ & $\begin{array}{c}\text { Musculo } \\
\text { skeletal }\end{array}$ \\
\hline \multirow[t]{3}{*}{ Caste } & ST & 3.7 & 9.9 & 39 & 22.7 & 4.2 \\
\hline & Non- & & & & & \\
\hline & ST & 21.4 & 19.3 & 12.9 & 12.3 & 11.7 \\
\hline MPCE & Low & 17.2 & 17.1 & 20.2 & 10.8 & 13.7 \\
\hline \multirow[t]{3}{*}{ group } & Medi & & & & & \\
\hline & um & 18.5 & 14.2 & 12.2 & 20.2 & 13.8 \\
\hline & High & 22.9 & 21.7 & 12.7 & 9.2 & 10.5 \\
\hline Total & & 21.3 & 19.3 & 13.1 & 12.3 & 11.7 \\
\hline
\end{tabular}

Source: Estimated from the unit level data of NSS $71^{\text {st }}$ Round, Key Indicators of Social Consumption in India: Health, 2014

The highest MPCE groups have higher occurrences of cardiovascular diseases (22.9 per cent), whereas the lowest MPCE groups suffered mainly infection type diseases (31.4 per cent). On the other hand, social group analysis shows that infection was the major ailment (39 per cent) followed by respiratory diseases (22.7 per 
cent)among the morbid ST persons, while cardio-vascular diseases were prominent among non-ST morbid respondents.

As far as the nature of ailment is concerned, among the morbid persons, hyper tension is the prominent ailment (15.5 per cent) followed by diabetes (14.2 per cent). Here also we can see a clear cut distinction among ST and non-ST households (Table 5). Among the ST households, the 'All other fevers' were prominent (30.8 per cent) followed by the disease like 'Cough with sputum with or without fever and NOT diagnosed as TB' (20.4 per cent).A similar pattern can also be seen among MPCE analysis also. 'All other fevers' were prominent among Low MPCE group (19.3 per cent) while hyper tension was prominent among high MPCE class (16.8 per cent) followed by diabetes (15.9 per cent).This analysis shows that though the ST respondents have reported low morbidity, the share of the respiratory diseases is very high compared to non-ST group. On the other hand, the highest MPCE group, who can be considered as highest income group also, is reporting higher morbidity, but mainly due to the higher occurrence of cardio-vascular diseases.

Table 5 Major types of ailment reported among Caste and MPCE groups in Kerala - 2014 (Percentage)

\begin{tabular}{llrrr}
\hline $\begin{array}{c}\text { Background } \\
\text { variables }\end{array}$ & \multirow{2}{*}{ Attributes } & \multicolumn{3}{c}{ Nature of ailment } \\
& & Hypertension & Diabetes & All other fevers* \\
\hline Caste & ST & 3.6 & 8.9 & 30.8 \\
& Non-ST & 15.6 & 14.3 & 12.1 \\
MPCE group & Low & 12 & 11.6 & 19.3 \\
& Medium & 13.2 & 11 & 11.4 \\
& High & 16.8 & 15.9 & 11.8 \\
Total & & 15.5 & 14.2 & 12.2 \\
\hline
\end{tabular}

\footnotetext{
* Includes malaria, typhoid and fevers of unknown origin, all specific fevers that do not have a confirmed diagnosis
}

Source: Estimated from the unit level data of NSS $71^{\text {st }}$ Round, Key Indicators of Social Consumption in India: Health, 2014

It is clear from the type and nature of ailment, that highest MPCE group suffers from lifestyle diseases, where as the ST group suffers from infectious diseases. In order to have a clear picture on this argument, an analysis on lifestyle diseases has been done in the following session. 


\section{Lifestyle diseases}

Lifestyle diseases are permanent and require long periods of excessive care and hence they are termed chronic diseases by medical practitioners, "which is putting pressure on the health care system. If uncurbed, a new generation of 'diseases of comfort' (chronic diseases caused by obesity and physical inactivity) will become a major public health problem in this and the next century" (Choi et al., 2005, p.1030).

For the sake of analysis, I have selected seven lifestyle diseases from a list of 61 in the NSSO Report. They are; (i) hypertension, (ii) diabetes, (iii) heart disease: chest pain, breathlessness, (iv) stroke/ hemiplegia/sudden onset weakness or loss of speech in half of body, (v) bronchial asthma/ recurrent episode of wheezing and breathlessness with or without cough over long periods or known asthma), (vi) obesity, and (vii) cancers

Table 6 Distribution of morbid persons among different socio-economic groups in Kerala 2014 Kerala - 2014 (Percentage)

\begin{tabular}{|c|c|c|c|c|}
\hline \multirow{2}{*}{\multicolumn{2}{|c|}{ Background variables }} & \multirow{2}{*}{ Attributes } & \multicolumn{2}{|c|}{ Lifestyle diseases (Percentage) } \\
\hline & & & Kerala & India \\
\hline \multirow{2}{*}{ Caste } & \multirow{6}{*}{ Quartile } & ST & 13.9 & 10.7 \\
\hline & & Non-ST & 43.1 & 28.8 \\
\hline \multirow{3}{*}{$\begin{array}{l}\text { MPCE } \\
\text { Group }\end{array}$} & & Low & 36.7 & 15.6 \\
\hline & & Medium & 40.0 & 24.8 \\
\hline & & High & 44.8 & 40.4 \\
\hline Total & & & 42.9 & 27.7 \\
\hline
\end{tabular}

Source: Estimated from the unit level data of NSS $71^{\text {st }}$ Round, Key Indicators of Social Consumption in India: Health, 2014

The occurrence of lifestyle diseases is very high in Kerala in comparison to the national average. While 42.9 percent of all morbid persons suffer from lifestyle diseases, the national average is much below at 35.4 percent. The occurrence of lifestyle diseases is high among highest MPCE group (44.8 per cent) while it is lowest in low MPCE group (36.7 per cent). The caste wise analysis shows that lifestyle diseases are very less among ST respondents (13.9 per cent) when compared to non-ST morbid persons (Table 6). 


\section{Multivariate analysis: Logistic Regression}

In order to discover the effect of selected background variables on reported lifestyle diseases of the morbid population, the logistic regression analysis has been carried out. In this analysis, reported lifestyle disease has been taken as dependent variable, while other variables such as caste, MPCE, age group, sex, size of household and area as independent variables. The odds ratio (exp (b)) shows the odds of reporting lifestyle diseases compared to the reference category, by considering the other variables constant. Here, reference category is the one with odds ratio being 1 .

The result shows that there is no indication of multi collinearity as there is no independent variable with standard error greater than 2.0.The relationship between the combinations of independent variables and dependent variable is based on final model's statistical significance of chi-square in the table. The probability of the model chi-square (2823038.713) was $<0.001$ (Table 10). The null hypothesis (i.e., there was no difference between the model without independent variables) has been rejected, and the relationship between the dependent variable and independent variables has been confirmed. All the variables were statistically significant at $<1$ $\%$ level, when the analysis was done with the projected population.

Logistic regression analysis shows that as far as caste group is concerned non-ST group has comparatively a higher chance to report more lifestyle diseases when compared to ST group. The non-ST group has 3 times more chance to have lifestyle disease when compared to ST group.

Table 10 Determinants of Lifestyle Disease: Logistic Regression Results

\begin{tabular}{llccr}
\hline $\begin{array}{c}\text { Independe } \\
\text { nt variables }\end{array}$ & \multicolumn{1}{c}{ Attributes } & B & S.E. & $\begin{array}{c}\text { OddsRatio } \\
(\operatorname{Exp}(\mathrm{B}))\end{array}$ \\
\hline Caste & ST & & & 1.000 \\
& Non-ST & 1.121 & 0.011 & 3.068 \\
MPCE & Low MPCE & & & 1.000 \\
Group & Medium MPCE & 0.122 & 0.003 & 1.130 \\
Age & High MPCE & 0.232 & 0.003 & 1.261 \\
Group & $0-4$ & & & 1.000 \\
& $5-14$ & 0.733 & 0.010 & 2.081 \\
& $15-34$ & 1.643 & 0.009 & 5.170 \\
& $35-59$ & 3.620 & 0.008 & 37.353 \\
\hline
\end{tabular}




\begin{tabular}{llclr}
\hline & 60 \& above & 4.319 & 0.008 & 75.113 \\
Sex & Male & & & 1.000 \\
& Female & -0.397 & 0.001 & 0.672 \\
Household & 3 \& below & & & 1.000 \\
size group & $4-5$ & 0.159 & 0.001 & 1.172 \\
& $6-7$ & 0.272 & 0.002 & 1.312 \\
& 8 \& Above & 0.198 & 0.003 & 1.219 \\
Place of & Rural & & & 1.000 \\
Residence $\quad$ Urban & -0.227 & 0.001 & 0.797 \\
Constant & & -4.942 & 0.014 & 0.007 \\
\hline Omnibus & Tests of Model & $=$ & $2823038.713, \mathrm{p}(0.000)$ \\
Coefficients Chi-square & & & \\
-2Log Likelihood & $=$ & 15253018.737 & \\
Cox \& Snell R Square & $=$ & 0.192 & \\
Nagelkerke R Square & $=$ & 0.258 &
\end{tabular}

Source: Estimated from the unit level data of NSS $71^{\text {st }}$ Round, Key Indicators of Social Consumption in India: Health, 2014

MPCE size and lifestyle disease showed a positive relationship. Highest chance to report lifestyle disease was shown in the highest MPCE group. The highest MPCE group was 26 per cent more likely to report an ailment than those of lowest MPCE group. As far as age group status is concerned, $60 \&$ above age group has comparatively a higher chance to report more lifestyle disease when compared to other age groups. They have 75 times more chance to be in lifestyle diseases when compared to the lowest age group. Morbid males were 32.8 per cent more likely to report a lifestyle disease than males. Morbid people from rural area were 20 per cent more likely to report a lifestyle disease than those in urban area.

The foregoing logistic regression analysis shows that the background variables like caste, MPCE, age, sex and area have statistically significant effect in determining lifestyle disease. One of the notable points in this analysis is that the lifestyle diseases are more prominent in highest MPCE groups, while lowest in ST groups.

The previous discussions show that the morbidity is higher among higher MPCE group (or rich group) and lower among ST group (the poorer group). This finding supports the first school of thought pertaining to morbidity patterns, as mentioned in the 
introduction; according to this school higher rate of morbidity mainly arises due to higher reportability of sickness which in turn is indebted to the higher educational levels and health care institutions prevailing in the state. As per the present study, one of the reasons for this phenomenon is the prevalence of type of diseases. Majority of the highest income group (or rich group) experience lifestyle diseases, but the ST (poorer) group mainly suffer from respiratory diseases. It can, more or less, be confirmed that the higher morbidity rate in Kerala is due to the higher prevalence of lifestyle diseases, as experienced by higher MPCE groups. On the other hand, the respiratory and epidemic diseases are on the rise in Kerala, especially in the recent periods, which effects mainly the lower strata including the ST and poor income groups.

\section{Conclusion}

The 'Low Mortality High Morbidity Syndrome' designates one of those crucial questions posed at the model followed by the state in this context. It is in this context, the present study tried to analyse the pattern of morbidity in Kerala and to find out the effect of selected background characteristics on lifestyle diseases of the morbid population. Morbidity is highest in Kerala among the Indian states. Highest morbidity is seen among highest MPCE group, while lowest is seen among ST households, who are considered to be the poorest of poor. The reasons for the lower morbidity in ST households and high morbidity in highest MPCE groups are due to the characteristics of the ailments. One of the reasons for the highest morbidity in Kerala is due to the occurrence of lifestyle diseases. The logistic regression analysis showed that the background variables like caste, MPCE, age, sex and place of residence have statistically significant effect in determining lifestyle diseases. The lifestyle diseases are more prominent in highest MPCE groups, while lowest in ST groups. This confirms that lifestyle diseases have a prominent role in determining the higher morbidity rates of the state. On the other hand the study also leads to the appalling finding thatthe respiratory and epidemic diseases are consistently on the rise in Kerala, especially in the recent period. While this has a generic appearance the study revealas that 
this is particularly so among the ST and poor income groups. This situation invites the government to think of some effective intervention plans and action programmes.

\section{References}

Ashokan, A. \& Ibrahim, P. (2007), “Kerala Under Morbidity Trap?”, Kerala Calling, March.

CDS-UN (1975).Poverty, Unemployment and Development Policy: A Case Study of Selected Issues with Reference to Kerala, Centre for Development Studies, Thiruvananthapuram.

Choi, Bernard C.K., Hunter, David J., Tsou, Walter \& Sainsburgy, Peter (2005), "Diseases of comfort: primary causes of death in the 22nd century", Journal of Epidemiology and Community Health, Vol. 59, No.12, pp.1030-1034.

Devika, J. and Rajasree, A. K. (2008). "Health, Democracy and Sickle-Cell Anaemia in Kerala", Economic and Political Weekly, Vol. 43, No. 45 (Nov. 8 - 14, 2008), pp. 25, 27-29.

Dilip, T. R. (2002). Understanding levels of morbidity and hospitalization in Kerala, India. Bulletin of the World Health Organization, 80(9), 746751. https:/ / doi.org/10.1590/S0042-96862002000900012

Duraisamy, P. (2001). Health status and curative health care in rural India. Retrieved from http://www.ncaer.org/Downloads/ Working Papers/wp78.pdf

Ekbal, B. (2006). "Kerala Health Sector: Crying for Cure", Kerala Calling, May.

Ekbal, B.,Jayasree, A.K; Urmila, K.E., Aslesh, O.P., Krishnanunni \& Renjith,P .(2013) Report on Health Status of Tribals in Attapady, Pariyaram Medical College Team.

Ghosh, S., \& Arokiasamy, P. (2009)."Morbidity in India”. Journal of Health Studies, 11, 136-148.

Government of Kerala (2006).Human Development Report 2005: Kerala, State Planning Board, Thiruvananthapuram.

Gumber, A. \& Berman, P. (1997). "Measurement and pattern of morbidity and utilization of health services: Some emerging issues from recent health surveys in India", Journal of Health and Population in Developing Countries, 1: 16-43.

Iyer, A. (2005). Gender, caste, class, and health care access Experiences of rural households in Koppal district, Karnataka. Small Grants Programme on Gender and Social Issues in Reproductive Health Research, Achutha Menon Centre for Health Science Studies, Sree ChitraTirunal Institute for Medical Sciences and Technology, Trivandrum. 
Kannan, K.P., Thankappan K.R.,KuttyV.R. \& Aravindan K.P. (1991).Health and Development in Rural Kerala: A Study of Linkages between SocioEconomic Status and Health Status, Kerala Shastra SahityaParishad, Kozhikode.

Krishnan, T. N. (1985). Health statistics in Kerala state, India. In Good health at low cost. Proceedings of a Conference held at the Bellagio Conference Center, Bellagio, Italy, April 29 - May 3, 1985. Sponsored by the Rockefeller Foundation. Edited by Scott B. Halstead, Julia A. Walsh, Kenneth S. Warren. (pp. 39-45).

Krishnaswami, P. (2004). Morbidity Study - Incidence, Prevalence, Consequences and Associates Kerala Research Programme on Local Level Development.

Kunhikannan, T. P. \& Aravindan, K. P. (2000).Changes in Health Status of Kerala 1987-1997, Discussion Paper No. 10. KRPLLD, Centre for Development Studies, Thiruvananthapuram.

Mohindra, K. S., Haddad, S., \& Narayana, D. (2006). Women's health in a rural community in Kerala, India: do caste and socioeconomic position matter? Journal of Epidemiology and Community Health, 60(12), 1020-6. https:/ / doi.org/10.1136/jech.2006.047647

Mukherjee, S., \& Levesque, J.-F. (2012). Morbidity and Outpatient Care for the Elderly in Kerala, South India: Evidence from a National Population based Survey. Journal of Population Ageing, 5(3), 177-192. https://doi.org/10.1007/s12062-012-9067-7

Murray, C.J.L. \& Chen, L.C. (1990). “Understanding morbidity change”, Population and Development Review, 18.

Nag, M. (1983). "The impact of social and economic development on mortality: A comparative study of Kerala and West Bengal", Economic and Political Weekly, 18-21.

Navaneetham K., Kabir M. \&Krishnakumar, C.S. (2009). Morbidity Patterns in Kerala: Levels And Determinants, Working Paper No. 411, Centre for Development Studies, Thiruvananthapuram.

Navaneetham, K., \& Dharmalingam, A. (2002).Utilization of maternal health care services in Southern India. Social Science \& Medicine, 55(10), 1849-69. Retrieved from http://www.ncbi.nlm.nih.gov/ pubmed/12383469

NSSO-National Sample Survey Organisation (1998).Morbidity and Treatment of Ailments, Department of Statistics, Government of India, New Delhi.

NSSO-National Sample Survey Organisation (2014).Key Indicators of Social Consumption in India: Health, NSS 71st Round, NSSK I (71125.0), Department of Statistics, Government of India, New Delhi. 
NSSO-National Sample Survey Organisation (2006), Morbidity, Health Care and the Condition of the Aged, NSSO 60th Round (January-June 2004), Report No. 507, p.5.

Sen, A. (1987). Food and Freedom, Sir John Crawford Memorial Lecturer, Washington DC, October 29.

Sen, A. (2002). Health: perception versus observation. Self reported morbidity has severe limitations and can be extremely misleading. BMJ, 324, 860-861. Retrieved from http://bmj.com/cgi/content/ full/324/7342/860

Suryanarayana, M.H. (2008).Morbidity and health Care in Kerala: A Distributional profile and implications, WP-2008-004, Indira Gandhi Institute of Development Research, Mumbai.

Tharakan, P. K. M. (2006). Kerala Model Revisited: New Problems, Fresh Challenges, (15), 1-108. Retrieved from http://www.csesindia.org/ admin/modules/cms/docs/publication/15.pdf

Veron, R. (2000). "Sustainability and the 'New' Kerala Model", in GovindanParayil (ed.), Kerala: The Development Experience, Reflections on Sustainability and Replicabiilty, Zed Books, London and New York, 212-30.

Scaria, R., Sumesh, K., \& Irfan, T. (2013)."Multi-dimensional Poverty Index (MPI) status of tribes in Attappady Block, Palakkad District, Kerala", Asian Journal of Management Research, Vol. 4, Issue 2. 